NASA Technical Memorandum 87098

\title{
Hollow Cathodes in \\ High Pressure Arc Discharges
}

Terry L. Hardy and Francis M. Curran

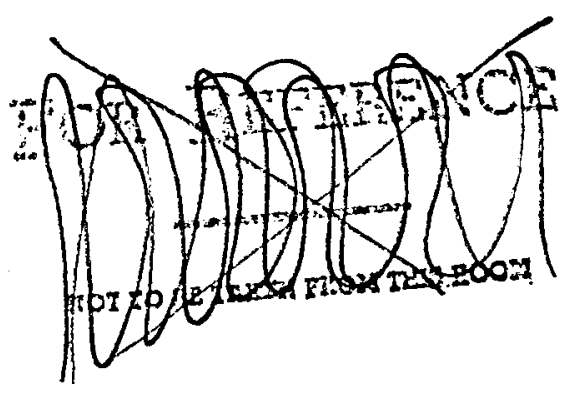

Lewis Research Center

Cleveland, Ohio

\section{Howndy dewery \\ DEC 971985 \\ LANGLEY RESEARCH CENTE? \\ LIBRARY, NASA \\ HAMPTON, VIRGINIA'}

Prepared for the

Eighteenth International Electric Propulsion Conference cosponsored by the AIAA, JSASS, and DGLR

Alexandria, Virginia, September 30-October 2, 1985 
AIAA-85-2035

Hollow Cathodes in High Pressure

Arc Discharges

T.L. Hardy and F.M. Curran, NASA Lewis

Research Center, Cleveland, $\mathrm{OH}$

\section{AIAA/DGLR/JSASS 18th International Electric Propulsion Conference September 30-October 2, 1985 Alexandria, Virginia}




\section{HOLLOW CATHODES IN HIGH PRESSURE ARC DISCHARGES}

Terry L. Hardy and Francis M. Curran

National Aeronautics and Space Administration

Lewis Research Center

Cleveland, Ohio 44135

\section{Abstract}

In an attempt to improve lifetime and efficiency in arcjet thrusters an orified hollow cathode was tested at high pressures. The results indicated that the arc would not operate with emission from the insert above 200 torr in nitrogen regardless of insert material, orifice diameter, or gas flow direction. Emission occurred from the insert in argon and xenon although it could not be ascertained whether diffuse or spot emission existed within the cathode. Over the extended range of configurations and operating parameters explored the desired diffuse emission mode could not be obtained at high enough pressures for orified hollow cathodes to operate in the range currently being considered for arcjet applications.

\section{Introduction}

Recent reevaluation of the possible benefits of arcjet thrusters in the field of auxiliary propulsion has led to research both at NASA Lewis Research Center $1-3$ and in industry. 4,5 For low-power arcjets to be feasible, improvements in cathode lifetime, operational stability and overall efficiency will be necessary. Similar problems encountered at Lewis Research Center ${ }^{6}$ and elsewhere with ion engines were reduced by incorporating orified hollow cathodes into the thruster design. This success motivated the studies described in this report. A major difference in cathode operation exists between the two designs in that the ion engine hollow cathode typicaliy operates at low pressure ( $<10$ torr) while the arcjet cathode, normally a solid rod configuration, is contained in a chamber near or above atmospheric pressure. In the ion engine the cathode runs in the "normal arc" mode in which primary electron emission is obtained from a large area of the insert interior surface. The total electron current is thought to be split fairly evenly between field-enhanced surface emission and volume ionization processes. 8 This quiescent mode of operation avoids the formation of localized cathode hot spots which can be very destructive. The experiments described in this report were designed to determine whether or not this type of behavior can be obtained at elevated pressure levels appropriate for arcjet operation.

\section{Apparatus}

A free-burning arc configuration was used to study the operation of the hollow cathode. In this configuration a direct-current arc discharge was maintained between two electrodes as shown in Fig. 1. Further details of this apparatus are given el sewhere. 9

Figure 2 is a schematic diagram of an orified hollow cathode similar to that used in ion thruster applications. 10 These cathodes were constructed of tantalum tubes, $0.64 \mathrm{~cm} 0 . d$.,
$0.53 \mathrm{~cm}$ i.d., $5.08 \mathrm{~cm}$ long, with 2 percent thoriated tungsten disks of various orifice diameters electron-beam welded to the tantalum tubes. Low work function inserts were placed inside the tube to provide the electron emission to sustain the discharge. These inserts were forced to butt against the thoriated tungsten disks. Three inserts were used in this configuration:

(1) Barium oxide - impregnated porous tungsten, $0.53 \mathrm{~cm} 0 . d$., $0.30 \mathrm{~cm}$ i.d., $2.54 \mathrm{~cm}$ long

(2) Lanthanum hexaboride insert, $0.53 \mathrm{~cm}$ o.d., $0.30 \mathrm{~cm} \mathrm{i.d.,} 2.54 \mathrm{~cm}$ long

(3) Rolled tantalum foil coated with R-500, a mixture of carbonates in an organic solvent. The foil insert was $2.54 \mathrm{~cm}$ long.

In addition to the orified hollow cathode two alternate cathode configurations were used, as shown in Fig. 3. The first configuration was a quartz hollow cathode. This cathode was constructed with a quartz disk, $0.089 \mathrm{~cm}$ diameter orifice, on the end of a $0.64 \mathrm{~cm} 0 . d$., $0.53 \mathrm{~cm}$ i.d. quartz tube. A lanthanum hexaboride insert was used in this configuration.

The second configuration was a hollow tube configuration. This cathode had a lanthanum hexaboride insert inside a $0.25 \mathrm{~cm} 0 . d$., $0.21 \mathrm{~cm}$ i.d. tantalum tube.

\section{Procedure}

Tests were performed to determine the operation of the orified hollow cathode with argon, xenon, nitrogen, and helium. Results are also presented on the operation of the quartz hollow cathode and the hollow tube cathode with both argon and nitrogen. In all three configurations the arc was started by an input of approximately $450 \mathrm{~V}$ at pressures ranging from 0.5 to 10 torr and a $0.3 \mathrm{~cm}$ gap between the electrodes. Argon at 0-100 SCCM was used in most tests to initiate the arc. Once a stable arc (emission from the insert material) had been achieved the background pressure was raised by an input of argon from an external port. For a given pressure the current and gas flow rate were varied between 5 to $12 \mathrm{~A}$ and 0 to 250 SCCM, respectively, to determine any change in operation. After the operation in argon had been characterized the chamber pressure was decreased to approximately 10 torr and nitrogen or helium was allowed to flow through the cathode. The background pressure was then raised and the cathode operation was determined at various pressures up to 760 torr for a range of currents and flow rates. Tests in xenon were performed as described above except that xenon was used to initiate the arc instead of argon. After the cathode operation had been observed for the full range of pressures the test was stopped and a new cathode with a different orifice diameter or 
insert material was placed in the chamber, and the test procedure was repeated.

Several operating parameters were varied with the orified hollow cathode. Tests were performed using both thoriated tungsten and copper anodes. The flow direction was reversed from the conventional flow through the cathode to flow from anode to cathode in some tests. Also, a vacuum was drawn on the cathode in an attempt to draw the arc to the insert. Finally, a tantalum wire heater was attached to the orified hollow cathode in a manner similar to ion thruster cathodes. This heater was placed on the cathode to provide even heating of the insert material.

\section{Results and Discussion}

The results from the orified hollow cathode tests in argon and xenon are presented in Table 1. With $\mathrm{Ar}$ as the working fluid and a $0.038 \mathrm{~cm}$ orifice the arc originated from the $L_{a B}$ insert up to a pressure of approximately 160 torr. At pressures above this level spot emission from the thoriated tungsten orifice plate was observed. Similar behavior was found using a $0.099 \mathrm{~cm}$ orifice in which a constricted arc mode with emission from the orifice plate was observed at about 600 torr.

It is important to note that although a number of cases yielded emission from the insert it cannot be concluded that the cathode was operating in the diffuse, or normal arc mode described previously. In fact, in some of the high pressure tests a localized hot spot was observed on the tantalum support tube. This probably indicates spot formation on the cathode interior. Figure 4 shows these modes of operation. Drawing a vacuum on the cathode side ( 4 to 20 torr) with a reverse flow pattern also allowed operation to 760 torr but a cathode spot occasionally appeared on the upstream side of the insert (i.e., on the tantalum support tube). Tests at pressures between 760 and 1520 torr were also performed with no change in operation. Changing the insert material also did not change cathode operation. Final tests with argon, using quartz hollow cathode with the $\mathrm{LaB}_{6}$ insert, also produced operation from the insert to pressures of 760 torr although, once again, spot emission or a constricted arc mode could not be differentiated from the normal arc mode.

Results from tests with Xe were similar to those obtained with argon in that stable operation from the insert could be obtained up to a pressure of 760 torr with an orifice diameter of $0.102 \mathrm{~cm}$. Operational difficulties were seen with xenon operation, however. In early trials the arc was seen to jump to the cathode body where wandered rapidly causing visible erosion. Once this had occurred restart from the insert proved impossible.

Perhaps more important than the results of the inert gas tests were those obtained when nitrogen was used as the propellant. Being the only molecular gas used in this study it most closely resembles a real, storable arcjet fuel. A number of experiments were performed with $\mathrm{N}_{2}$, referring to Table 2, using differing orifice diameters, varying flow rates, etc. In each case the arc moved from the insert to the orifice plate as the pressure in the chamber was increased. In none of the configurations tried could emission from the insert be obtained at pressures greater than about 200 torr. This is well below the typical chamber pressure employed in arcjet thrusters. The flow rates employed in this study were also well below realistic operating flow rates (i.e., $<300$ SCCM for $\mathrm{N}_{2}$ ). Reversal of the flow direction did not affect results significantly al though the arc voltage did increase by 2 to $5 \mathrm{~V}$. Also, with $\mathrm{N}_{2}$, the arc could not be sustained at chamber pressures above 50 tor $r$ when the vacuum was drawn on the cathode side.

The choice of insert material had little effect on the mode of operation although the arc voltage was affected. Addition of a cathode heater (tantalum) also did not affect operation although exterior spot formation in $\mathrm{N}_{2}$ at $\mathrm{high}$ pressure did originate from the heater.

Tests performed in helium were also unsuccessful in that emission from the insert could not be obtained even below 50 torr.

In a final set of experiments unorified cathodes were used, i.e., hollow support tube and insert without orifice plate, as shown in Fig. 3. In these experiments the cathode spot was observed on the exposed front face of the cathode insert for both $\mathrm{Ar}$ and $\mathrm{N}_{2}$. With either gas sporadic movement of the spot around the face was observed.

The results presented to this point agree closely, at least in a qualitative sense, with results obtained in other free-burning arc tests performed at Lewis Research Center. In these tests a number of cathode/anode combinations were used and a transition from diffuse to constricted cathode spot was always observed as the pressure increased. When thoriated tungsten rods, ground to allow gas flow, were used as cathodes with solid thoriated tungsten anodes argon arcs would rarely take the shortest path from cathode to anode. Arc attachments would generally occur near the brass (or copper) electrode supports. Under nitrogen the arc generally originated at or near the tip of the electrode and preferred a short path to the anode. The reported results suggest that it may not be possible to prevent transition from the normal arc mode of operation to the constricted spot mode in the pressure regime typically encountered in the arcjet thrust chamber (i.e, >500 torr). This has also been observed by others in the field. 11 Although emission processes from the interior of the hollow cathode are not completely understood it is evident that there is a critical pressure level at which diffuse thermal emission from the insert surface (coupled with associated volume ionization processes) can no longer sustain the discharge current level. At this point spot emission will result.

\section{Concluding Remarks}

Improvements in operational stability, reliabi]ity, cathode lifetime, and overall energy efficiency must be achieved before the arcjet can be successfully applied to the field of auxiliary propulsion. As the hollow cathode, operating in the low pressure regime, was successful in ail of these areas when used in the ion engine its characteristics were studied in the high pressure regime at which arcjets are expected to operate. 
In the free-burning arc configuration studied, flow direction, insert material, anode material, orifice diameter, and internal cathode pressure were varied to determine the operation of the orified hollow cathode. In all cases at elevated pressures ( $>200$ torr) in nitrogen operation was consistentiy from the constricted or spot mode with the point of cathode attachment on the orifice plate. Stable operation from the cathode insert with xenon as the working fluid was only obtained after several attempts led to erratic operation from the holder and orifice plate. In all tests, carefuliy controlled starting procedures were necessary. These findings indicate that incorporation of the orified hollow cathode would not be advantageous in arcjet thrusters of the conventional design. However, the results do not preclude the use of hollow cathodes in other, chambered designs nor do they preclude the introduction of a modified hollow cathode which could be forced into a diffuse mode of operation from the insert.

\section{References}

1. Nakanishi, S., "Performance Evaluation of a $1 \mathrm{~kW}$ Arcjet Thruster," presented at 18th International Electric Propulsion Conference A lexandria, VA, Sept. 30 - Oct. 2, 1985, AIAA Paper 85-2033.

2. Curran, F.M., "An Experimental Study of Energy Loss Mechanisms and Efficiency Considerations in the Low Power DC Arcjet," presented at 18th International Electric Propulsion Conference, Alexandria, VA Sept. 30 - 0ct. 2, 1985, AIAA Paper 85-2017.
3. Hardy, T.L., and Nakanishi, S., "Cathode Degradation and Erosion in High Pressure ArC Discharges," Proceedings of International Electric Propulsion Conference 17th, Tokyo, Japan, May 28-31, 1984, pp. 560-573.

4. Cann, G. private communication

5. Smith, W.W. private communication

6. Rawlin, V.K.; and Kerslake, W.R., "SERT II ; Durability of the Hollow Cathode and Future Applications of Hollow Cathodes," Journal of Spacecraft and Rockets, Vol. 7, No. 1, Jan. $1970, \mathrm{pp} .14-20$.

7. Sohi, G., Foshight, V.V., and Goldner, S.J., "Electron-Bombardment Cesium Ion Engine Systems," Electro-0ptical Systems, Inc., Pasadena, CA, 1967. (NASA CR-54711)

8. Siegfried, D. and Wilbur, P.J., "A Model for Mercury Orificed Hollow Cathodes - Theory and Experiment," AIAA Journal, Vol. 22, No. 10, 0ct. 1984, pp. 1405-1412.

9. Hardy, T.L. "Electrode Erosion in ArC Discharges at Atmospheric Pressure," Presented at 18 th International Electric Propulsion Conference, Alexandria, VA, Sept. 30 - 0ct. 2, 1985, AIAA Paper 85-2018.

10. Mirtrich, M.J., "Investigation of Hollow Cathode Performance for 30-cm Thrusters," AIAA Paper 73-1138, Nov. 1973.

11. Wilbur, P. private communication 
TABLE 1. - ORIFIEO HOLLOW CATHODE OPERATION IN Ar, Xe

\begin{tabular}{|c|c|c|c|c|c|c|c|c|}
\hline $\begin{array}{c}\text { Orifice } \\
\text { diameter, } \\
\mathrm{cm}\end{array}$ & $\begin{array}{c}\text { Insert } \\
\text { material }\end{array}$ & $\begin{array}{c}\text { Anode } \\
\text { material }\end{array}$ & Gas & $\begin{array}{l}\text { Flow, } \\
\text { SCCM }\end{array}$ & $\begin{array}{c}\text { Chamber } \\
\text { pressure, } \\
\text { torr }\end{array}$ & $\begin{array}{c}\text { Current, } \\
\text { A }\end{array}$ & $\underset{V}{\text { Voltage, }}$ & Comments \\
\hline 0.038 & $\mathrm{LaB}_{6}$ & $\mathrm{Cu}$ & Ar & $180-225$ & $10-160$ & 9 & 30 & $\begin{array}{l}\text { Above } 225 \mathrm{SCCM}, 160 \text { torr arc } \\
\text { moved to } \mathrm{ThO}_{2}-\mathrm{W}\end{array}$ \\
\hline .099 & $\mathrm{LaB}_{6}$ & $\mathrm{Cu}$ & Ar & $\begin{array}{l}40-250 \\
40-200\end{array}$ & $\begin{array}{l}50-600 \\
>600\end{array}$ & $5-10$ & $21+2$ & $\begin{array}{l}\text { Stable arc from insert below } \\
600 \text { torr; are on } \mathrm{ThO}_{2}-\mathrm{W} \text { above } \\
600 \text { torr }\end{array}$ \\
\hline .160 & $\mathrm{LaB}_{6}$ & $\mathrm{Cu}$ & Ar & $0-300$ & $1-760$ & $5-9$ & $21+1$ & $\begin{array}{l}\text { Stable arc (Emission from } \\
\text { insert) }\end{array}$ \\
\hline .206 & $\mathrm{LaB}_{6}$ & $\mathrm{Cu}$ & Ar & $0-200$ & $1-760$ & $6-12$ & $21+2$ & Stable arc \\
\hline .254 & $\mathrm{LaB}_{6}$ & $\mathrm{Cu}$ & Ar & $0-100$ & $1-760$ & $6-8$ & $19+3$ & Stable arc \\
\hline .279 & $\mathrm{LaB}_{6}$ & $\mathrm{Cu}$ & Ar & 100 & $1-760$ & $5-7$ & $20+2$ & Stable arc \\
\hline .099 & $\mathrm{LaB}_{6}$ & $\mathrm{ThO}_{2}-\mathrm{W}$ & Ar & 100 & $1-760$ & 9 & $17 \pm 2$ & Stable arc \\
\hline .099 & $\mathrm{LaB}_{6}$ & $\mathrm{ThO}_{2}-\mathrm{W}$ & Ar & 100 & $1-760$ & 9 & $23+2$ & Reverse flow; stable arc \\
\hline .099 & $\mathrm{LaB}_{6}$ & $\mathrm{ThO}_{2}-\mathrm{W}$ & Ar & 100 & $1-760$ & $5-10$ & $18+1$ & $\begin{array}{l}\text { Reverse flow, vacuum on cathode } \\
\text { stable arc }\end{array}$ \\
\hline .150 & Ta foil & W & Ar & 100 & $1-760$ & 10 & $17+2$ & Stable arc \\
\hline .150 & $\begin{array}{l}\text { Ba0-W } \\
\text { with heater }\end{array}$ & W & Ar & 100 & $1-760$ & 10 & ---- & Stable arc \\
\hline .150 & $\begin{array}{l}\text { BaO-W } \\
\text { no heater }\end{array}$ & $W$ & Ar & 100 & $1-760$ & 10 & 23 & Stable arc \\
\hline .102 & $\mathrm{LaB}_{6}$ & $\mathrm{Cu}$ & $x e$ & $0-200$ & $1-760$ & $5-10$ & ---- & Stable arc \\
\hline
\end{tabular}


TABLE 2. - ORIFIED HOLLOW CATHODE OPERATION IN N 2 , He

\begin{tabular}{|c|c|c|c|c|c|c|c|c|}
\hline $\begin{array}{c}\text { Orifice } \\
\text { diameter, } \\
\mathrm{cm}\end{array}$ & $\begin{array}{c}\text { Insert } \\
\text { material }\end{array}$ & $\begin{array}{c}\text { Anode } \\
\text { material }\end{array}$ & Gas & $\begin{array}{l}\text { Flow, } \\
\text { SCCM }\end{array}$ & $\begin{array}{c}\text { Chamber } \\
\text { pressure, } \\
\text { torr }\end{array}$ & $\begin{array}{c}\text { Current, } \\
\text { A }\end{array}$ & $\underset{V}{\text { Voltage, }}$ & Comments \\
\hline 0.038 & $\mathrm{LaB}_{6}$ & $\mathrm{Cu}$ & $\mathrm{N}_{2}$ & $180-225$ & 30 & 9 & $46+5$ & Arc on $\mathrm{ThO}_{2}-\mathrm{W}$ orifice plate \\
\hline .099 & $\mathrm{LaB}_{6}$ & $\mathrm{Cu}$ & $\mathrm{N}_{2}$ & $75-200$ & $\begin{array}{l}35-200 \\
>200\end{array}$ & $5-10$ & $44 \pm 5$ & $\begin{array}{l}\text { Stable arc } 35-200 \text { torr; arc on } \\
\mathrm{ThO}_{2}-\mathrm{W} \text { above } 200 \text { torr }\end{array}$ \\
\hline .160 & $\mathrm{La8}_{6}$ & $\mathrm{Cu}$ & $\mathrm{N}_{2}$ & $0-200$ & $\begin{array}{l}50-200 \\
>200\end{array}$ & $5-9$ & $43+5$ & $\begin{array}{l}\text { Arc appeared to be on insert to } \\
200 \text { torr; }>200 \text { torr arc on } \\
\text { orifice plate }\end{array}$ \\
\hline .206 & $\mathrm{LaB}_{6}$ & $\mathrm{Cu}$ & $\mathrm{N}_{2}$ & $0-100$ & $1-760$ & $6-12$ & $37+4$ & Arc on $\mathrm{ThO}_{2}-\mathrm{W}$ \\
\hline .254 & $\mathrm{LaB}_{6}$ & $\mathrm{Cu}$ & $\mathrm{N}_{2}$ & $30-50$ & $>200$ & $6-8$ & $38+5$ & Arc on $\mathrm{ThO}_{2}-W$ orifice plate \\
\hline .279 & $\mathrm{LaB}_{6}$ & $\mathrm{Cu}$ & $\mathrm{N}_{2}$ & 100 & $>50$ & $5-7$ & $40+4$ & Arc extinguished \\
\hline .099 & $\mathrm{LaB}_{6}$ & $\mathrm{ThO}_{2}-\mathrm{W}$ & $\mathrm{N}_{2}$ & 100 & $>120$ & و & $34+3$ & Arc on $\mathrm{ThO}_{2}-\mathrm{W}$ orifice plate \\
\hline .099 & $\mathrm{LaB}_{6}$ & $\mathrm{ThO}_{2}-\mathrm{W}$ & $\mathrm{N}_{2}$ & 100 & $>50$ & 9 & $36 \pm 4$ & $\begin{array}{l}\text { Reverse flow; arc on } \mathrm{ThO}_{2}-\mathrm{W} \\
\text { orifice plate }\end{array}$ \\
\hline .099 & $\mathrm{LaB}_{6}$ & $\mathrm{ThO}_{2}-\mathrm{W}$ & $\mathrm{N}_{2}$ & 100 & 50 & 10 & --- & $\begin{array}{l}\text { Reverse flow, vacuum on cathode } \\
\text { arc extinguished }\end{array}$ \\
\hline .150 & Ta foil & $W$ & $N_{2}$ & 100 & $>100$ & 10 & $36 \pm 4$ & Arc on $\mathrm{ThO}_{2}-W$ orifice plate \\
\hline .150 & $\begin{array}{l}\mathrm{BaO}-\mathrm{W} \\
\text { with heater }\end{array}$ & $w$ & $N_{2}$ & 100 & $<760$ & 10 & $35 \pm 3$ & Arc on heater \\
\hline .150 & $\begin{array}{c}\mathrm{BaO}-\mathrm{W} \\
\text { no heater }\end{array}$ & $w$ & $\mathrm{~N}_{2}$ & 100 & $<760$ & 10 & $-\cdots$ & Arc extinguished \\
\hline .102 & $\mathrm{LaB}_{6}$ & $\mathrm{Cu}$ & $\mathrm{He}$ & $0-100$ & $<50$ & $5-10$ & --- & $\begin{array}{l}\text { Could not obtain are from } \\
\text { insert }\end{array}$ \\
\hline
\end{tabular}




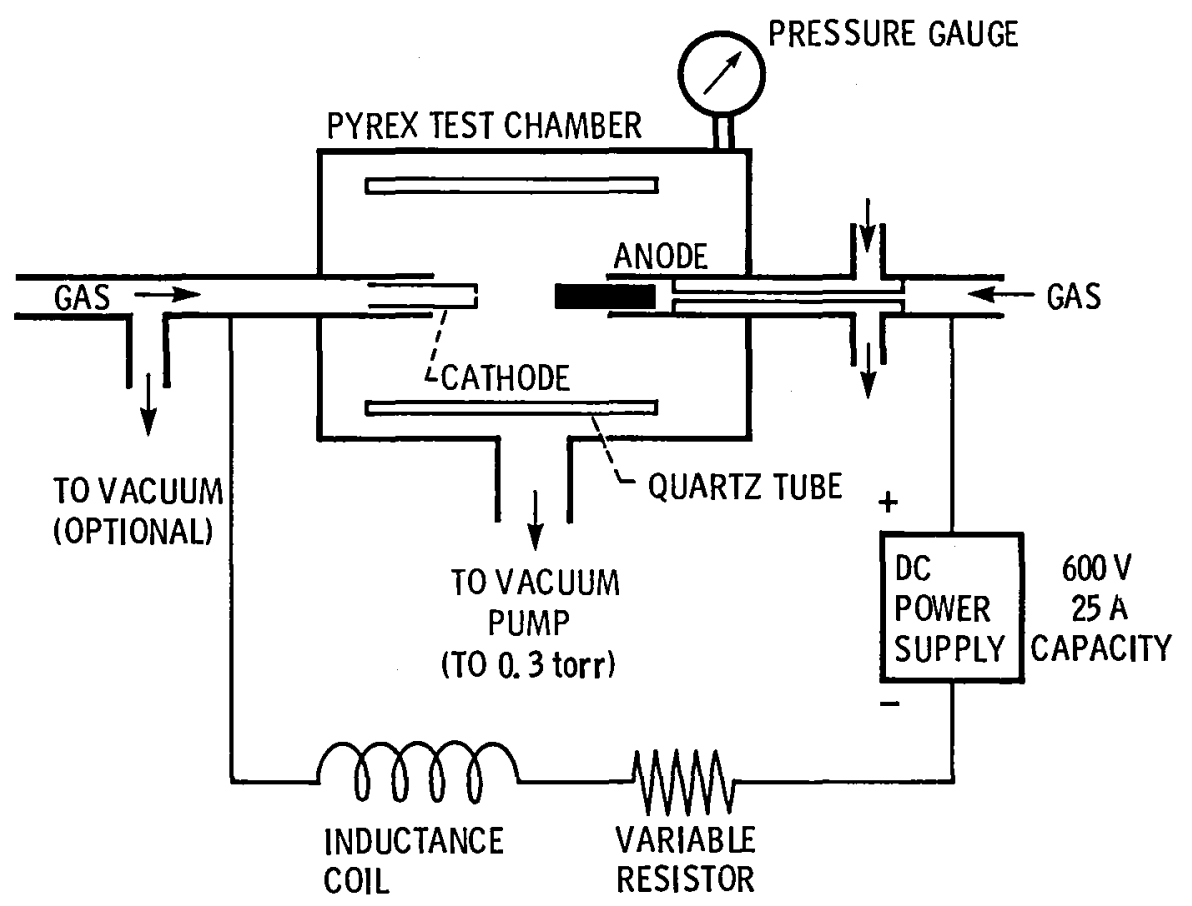

Figure 1. - Hollow cathode experimental apparatus.

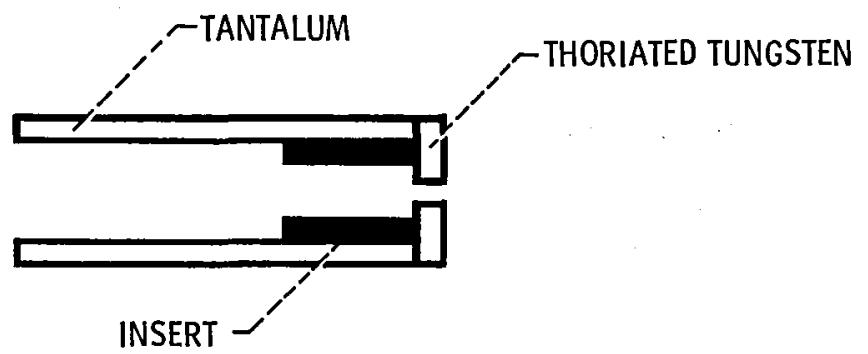

Figure 2. - Orified hollow cathode. 


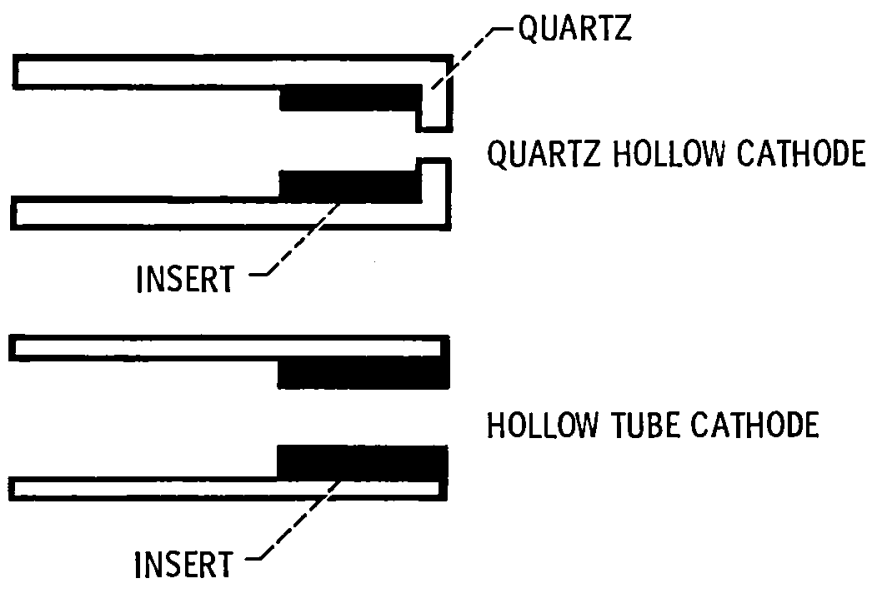

Figure 3. - Alternate cathode configurations.

ARC DISCHARGE

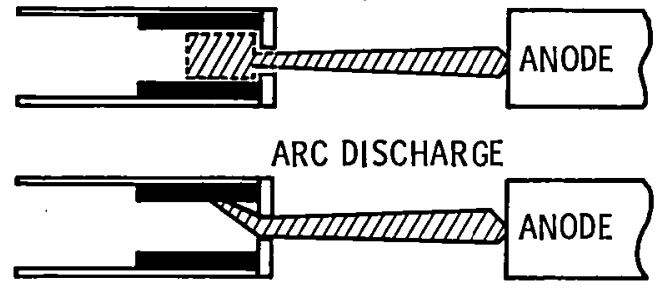

(a) Diffuse arc mode with arc from insert.

(b) Constricted arc mode with arc from insert.

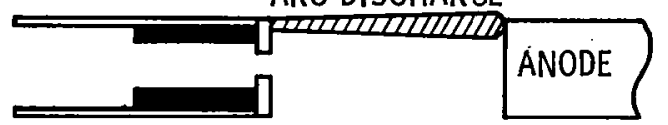

(c) Constricted arc mode with arc from orifice plate.

Figure 4. - Hollow cathode modes of operation. 


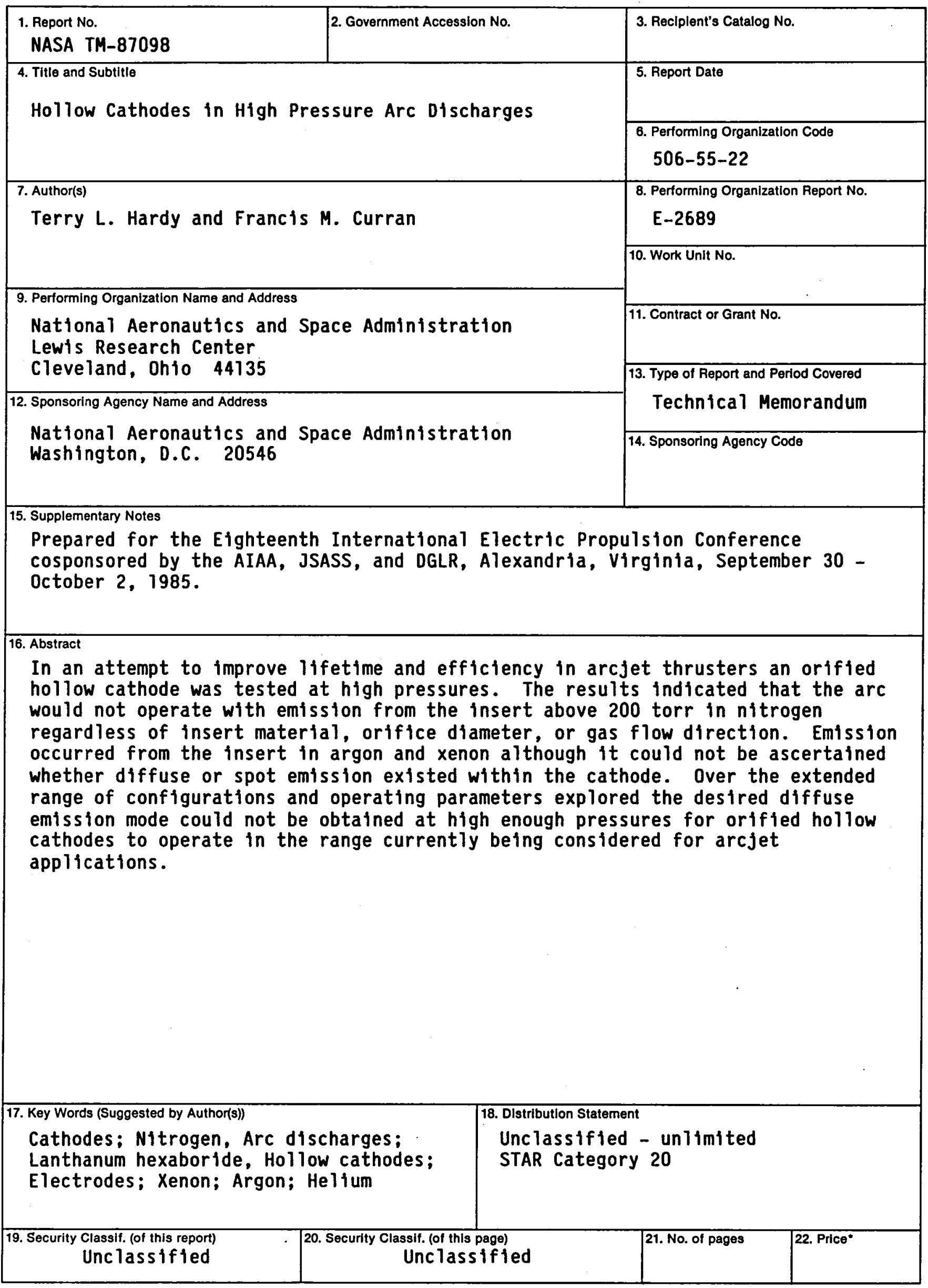

"For sale by the National Technical Information Service, Springfield, Virginia 22161 
End of Document 